Ryan Miller, Do

Department of of Infectious Disease,

Respiratory Institute, Cleveland Clinic
Kristin Englund, MD

Department of of Infectious Disease,

Respiratory Institute, Cleveland Clinic

\title{
Transmission and risk factors of COVID-19
}

\section{Posted April 14, 2020}

\section{ABSTRACT}

SARS-CoV-2, the virus that causes COVID-19, is transmitted through respiratory secretions and saliva. The virus can also live for short periods of time (1 to several hours) on fomites such as doorknobs, handrails, and tables. Aerosolization of the virus can occur during procedures including bronchoscopy, endotracheal intubation, and administration of nebulized treatments. Asymptomatic shedding of the virus does occur and may account for up to $60 \%$ of cases. Risk factors for a more severe course of COVID-19 include age 65 and older, living in a nursing home or long term care facility, chronic lung disease, and others.

\section{COVID-19 TRANSMISSION}

The virus that causes COVID-19 infection, SARS$\mathrm{CoV}-2$, is transmitted through respiratory secretions and saliva. ${ }^{1}$ Droplets are expelled through coughing or sneezing and can either land directly on the mucous membranes of another person (eg, mouth, eyes, and nose) or on the skin of another person who then touches his or her mucous membranes. The virus can also live for short periods of time (1 to several hours) on fomites such as doorknobs, handrails, and tables. ${ }^{1}$ The viability of the virus on fomites depends on the material of the object as well as exposure to the sun and environmental elements. Frequently touched objects (subway railings, door handles) should be cleaned with appropriate antiviral solutions at least every 24 hours.

The reproductive number (R0) or number of cases an infected person will cause during his or her infectious period for SARS-CoV-2 is 2.28 based on the outbreak on the Diamond Princess cruise ship. ${ }^{2}$ In contrast, the $\mathrm{R} 0$ for measles ranges from 12 to 18

The statements and opinions expressed in COVID-19 Curbside Consults are based on experience and the available literature as of the date posted. While we try to regularly update this content, any offered recommendations cannot be substituted for the clinical judgment of clinicians caring for individual patients.

doi:10.3949/ccjm.87a.ccc029 and the R0 for influenza ranges from 0.9 to 2.1. Animals have also been reported to carry SARS-CoV-2, including the large cats in the New York City zoo, but no cases of pet-to-owner transmission have been reported. ${ }^{3}$

Aerosolization of the virus can occur during bronchoscopy, endotracheal intubation, administration of nebulized treatments, manual bag ventilation before intubation, pronation of a patient, tracheostomy, and cardiopulmonary resuscitation. During these procedures, providers should wear N95 masks, eye shields, gowns, and gloves. Stool shedding of SARS-CoV-2 has been described, but it is unclear if transmission can occur via exposure.

Asymptomatic shedding of the virus does occur and may account for up to $60 \%$ of cases. Prior to the onset symptoms, people who do not practice appropriate social distancing or hand hygiene can unsuspectingly infect those around them. Viral shedding can occur up to 5 days before symptom onset. ${ }^{4}$

Homemade cloth masks are not considered personal protective equipment because they do not filter out tiny viral particles. However, they provide a means of slowing the spread of the virus and should be used in public settings where social distancing is difficult such as grocery stores. Once the cloth masks are removed, wearers must wash their hands because the front of the mask may carry mucous particles with virus. Also, the masks should be washed daily in a washing machine if used regularly.

Risk factors for a more severe course of COVID-19 currently include people who are or have:

- Age 65 and older

- Living in a nursing home or long term care facility

- Chronic lung disease

- Moderate to severe asthma

- Serious heart conditions

- Receiving chemotherapy

- A history of bone marrow or organ transplant 
- Immune deficiencies

- Poorly controlled HIV/AIDS

- A history of long-term use of steroids or other immunosuppressant drugs

- A history of tobacco smoking (and possibly vaping as well)

- A body mass index of 40 or greater

- Diabetes

- Chronic kidney disease on dialysis

- Liver disease. ${ }^{5}$

Dr. Anthony Fauci, MD, Director of the National Institute of Allergy and Infectious Diseases, commented publicly during a recent White House press conference that while African Americans are not being infected with SARS-CoV-2 more frequently than people of other races, they do seem to be dying at greater rates, possibly because they have a larger number of comorbidities.

\section{REFERENCES}

1. World Health Organization. Modes of transmission of virus causing COVID-19: implications for IPC precaution recommendations (Scientific Brief). https://www.who.int/news-room/commentaries/detail/ modes-of-transmission-of-virus-causing-covid-19-implications-foripc-precaution-recommendations. Updated March 29, 2020. Last accessed April 13, 2020.

2. Zhang S, Diao M, Yu W, Pei L, Lin Z, Chen D. Estimation of the reproductive number of novel coronavirus (COVID-19) and the probable outbreak size on the Diamond Princess cruise ship: A data-driven analysis. Int J Infect Dis 2020; 93:201-204. doi: 10.1016/j. ijid.2020.02.033

3. Centers for Disease Control and Prevention. If You Have Animals. https://www.cdc.gov/coronavirus/2019-ncov/daily-life-coping/animals.html. Last Updated March 27, 2020. Last Accessed April 13, 20202.

4. Zou, L. Ruan F, Huang M, et al. SARS-CoV-2 Viral Load in Upper Respiratory Specimens of Infected Patients. N Engl J Med 2020; 382(12):1177-1179. doi: 10.1056/NEJMc2001737

5. Centers for Disease Control and Prevention. Groups at Higher Risk for Severe Illness. www.cdc.gov/coronavirus/2019-ncov/need-extraprecautions/groups-at-higher-risk.html. Last Updated April 2, 2020. Last accessed April 13, 2020. 